\title{
AUTONOMIA NO JOGO DA LEITURA
}

\section{A leitura encarada como exercício lúdico e livre colabora para que as relações entre texto e leitor se deêm sem traumas e medo de erro, colocando em movimento os saberes e as habilidades de cada um}

Michel Picard, em A leitura como jogo $^{1}$, compara a leitura de textos ficcionais a um jogo, no qual o leitor desempenha papel preponderante. Esse trabalho diferencia-se do de outros estetas, na medida em que, para ele, o jogo não se circunscreve ao processo de criação artística, mas constitui o ato de ler em si. Nesse sentido, compete ao leitor estabelecer as regras do jogo, organizar seu modo de jogar, aproximando-se ou distanciando-se das convenções criadas pelo escritor.

No primeiro capítulo, "O jogo e sua função", Picard revê teorias e estudos relativos ao jogo, em vários campos do conhecimento: sociologia, psicologia, história, psicanálise, filosofia, bem como levanta aspectos comuns e divergentes entre os autores, propondo uma teoria que dê status epistemológico preciso à leitura enquanto jogo.

Muitas das reflexões do autor fundamentam este artigo que pretende abordar o ensino de leitura sob o enfoque do jogo.

A concepção de que o jogo se opõe ao sério, ao real, ao útil, ao fecundo, enfim, ao trabalho está presente na maioria dos estudos realizados. Embora se reconheça sua importância, tanto nas sociedades primitivas quanto nas contemporâneas, o jogo é considerado sempre em oposição ao trabalho. Tal oposição evidencia-se, seja na forma de diversão, contrapondose ao trabalho, seja na forma de preparação para o trabalho, independente de sua classificação em ludus ou paidéia. $\mathrm{O}$ termo ludus referese ao jogo como conjunto de regras e conven- ções que devem ser observadas e seguidas, enquanto paidéia se refere ao jogo como forma de evasão, de libertação, de fantasia.

Huizinga afirma: "O jogo é uma ação livre, sentida como fictícia e situada fora da vida normal, comum, capaz no entanto de absorver totalmente o jogador; uma ação destituída de todo interesse material e de toda utilidade; que se realiza em um tempo e espaço expressamente circunscritos; se desenvolve com ordem, segundo regras dadas e suscita, na vida, relações de grupos, envolvendo-se voluntariamente em mistérios" 2 .

Assim, a principal característica do jogo seria a de envolver o ser humano completamente, transportando-o para espaços e tempos diversos do real. Afastando-o do trabalho, das obrigações diárias, o jogo em suas diversas formas (competição, simulação, azar) teria o poder de liberar emoções, refazer o psiquismo, unir pessoas e grupos.

A vertente que aproxima o jogo do trabalho, mostrando-o como preparação para o trabalho e a vida, encontra-se nos estudos de Piaget, sobre o papel do jogo na infância.

\begin{tabular}{l}
\hline A AUTORA \\
\hline Alice Vieira \\
Professora Doutora da Faculdade de Educação-USP. \\
Coordenadora do Laboratório de Leitura da FEUSP. \\
Autora do livro O prazer do texto (Ed. EPU); co- \\
autora: O ensino de português do primeiro grau à \\
universidade (Ed. Contexto) e Universos da \\
palavra: da alfabetização à leitura (Ed. Iglu).
\end{tabular}


Para ele, o jogo exerce função capital no processo de assimilação, opondo-se à imitação que se insere na esfera da acomodação. Em seu desenvolvimento, a criança passa por fases em que o jogo apresenta natureza diversa: de imitação, simbólico, de exercícios, de regras. Entre elas, o jogo simbólico desempenha papel essencial na formação da função simbólica e, conseqüentemente, no desenvolvimento da linguagem, uma vez que possibilita a diferenciação e coordenação entre significante e significado.

Ao descrever o caminho percorrido pelo indivíduo, da infância à vida adulta, no trabalho, ao pensamento adaptado, Piaget destaca a importância dos jogos, a partir da formação da função simbólica, dizendo: "Há continuidade, na criança, entre o jogo e o trabalho. (...) Os jogos de construção são a fronteira ligando o jogo a condutas não-lúdicas" 3 . Os jogos seriam, então, uma preparação para a vida adulta, para o trabalho.

Segundo Picard, a relação entre jogo e trabalho decorre da natureza dos estudos realizados, que se atêm a estruturas exteriores, formas e regras e não às necessidades que o jogo satisfaz no homem.

"A criança é um ser que joga e nada mais", é uma das conclusões das investigações que procuram analisar a função do jogo na vida humana. As análises freudianas e de cunho psicanalítico defendem a tese de que o jogo satisfaz as necessidades vitais, preserva a vida e compensa lacunas. $\mathrm{O}$ jogo aí não é examinado sob o ponto de vista de suas estruturas externas, mas é inerente à essência humana.

De acordo com Benveniste, "a consciência está condenada a tatear dolorosamente em um real que ela não pode viver instantaneamente, nem assumir completamente (...) Para tornar-se real segundo suas tendências mais profundas, a consciência deve-se tornar irreal, segundo o universo. Eis onde o jogo intervém" 4 .

$\mathrm{O}$ jogo adquire, desse modo, o papel de retificador da realidade; quando ela não o satisfaz, o homem recorre ao jogo. Ele funciona como um mecanismo de defesa e de construção, de adaptação e de equilíbrio frente às agressões e frustrações que a vida proporciona.

Por meio do jogo, três momentos do tempo se articulam: presente, passado e futuro. O presente capaz de despertar grandes desejos no homem, o passado pela lembrança das satisfações infantis desses desejos e o futuro como campo de sua possível realização.

Held, num caminho inverso, estudando a necessidade da ficção (o imaginário) e da arte na vida da criança e do adulto, como fator de equilíbrio psíquico, escreve:

"A criança, para se desenvolver de maneira equilibrada, harmoniosa, tem necessidade de sonho, de imaginário. A criança que não encontrar ao seu alcance as vias sãs da imaginação que são oferecidas pelo conto, pela poesia, pela pintura, pela música e por qualquer forma de arte em geral, corre o risco de tornar-se um adulto que investe sua capacidade de sonho e a satisfaz no páreo triplo, nos horóscopos ou na loteria federal"'5.

No jogo de relações que se tece entre arte e jogo, em alguns casos, o chamado jogo de azar substitui, no adulto, a arte, $o$ anseio pela ficção, preenchendo, às vezes, deficientemente, lacunas existenciais.

$\mathrm{Se}$ o jogo responde e corresponde às necessidades primordiais do homem, estabelece e restabelece seu equilíbrio psíquico, adaptando-o ao mundo real, e se a criança é um ser que joga, que papel representa a leitura na vida da criança?

5. HELD, Jaqueline. O imaginário no poder. São Paulo: Summus, 1980, p. 174. 


\section{A LEITURA COMO JOGO}

Um jogo, entre outros jogos, talvez seja esta a resposta que melhor expresse a representação que a criança faz da leitura, em seu cotidiano. Para algumas, a leitura ocupa quase toda a parte lúdica. Em As palavras ${ }^{6}$, Sartre revela que a leitura constituía, praticamente, seu único jogo, seu mundo de sonho, de evasão. Escondido no sótão, na biblioteca, debaixo da mesa, ficção e realidade entrelaçavam-se, enredavam-se, num jogo em que as fronteiras tornavam-se cada vez mais tênues, mais frágeis.

Lançando um olhar sobre sua infância, à procura do tempo perdido, Proust ${ }^{7}$ relembra certas férias passadas no interior da França, na casa dos tios. Sentado à beira do lago, em cima dos galhos de uma árvore, num canto da sala ou em seu quarto, a leitura de romances o absorvia de tal maneira que ele não sentia vontade de comer, de passear, de brincar. A leitura era seu jogo, seu passatempo, sua brincadeira.

$\mathrm{O}$ jogo, no sentido de paidéia, de fantasia, pode ser a leitura descompromissada, aquela em que se entra pelas vias da imaginação, da fantasia, da emoção. Local onde as regras foram suprimidas. A senha de entrada é o imaginário, o fantástico, a identificação. Entra-se pela porta do sonho.

A leitura-paidéia deve ser estimulada, incentivada, em casa, na escola, na sala de leitura, na biblioteca, desde o início da infância. Com ela, a criança brinca de faz-de-conta, e pode, ainda que inconscientemente, resolver problemas de relacionamento, carências afetivas, medos, angústias.

Lendo ou ouvindo contos de fadas, narrativas tradicionais, lendas, histórias infantis, poemas, a criança desenvolve a imaginação, identifica-se com personagens, vivencia situações distantes no tempo e no espaço, suprindo suas necessidades.
Mas, há jogos e jogos. A leitura também se estrutura como outra forma de jogo, o ludus, com regras e convenções, que devem ser ensinadas, conhecidas e seguidas.

A leitura-ludus se inicia. De um lado, um jogador experiente, certo de sua vitória; de outro, jogadores inexperientes, temerosos de perder. Para que não haja cartas marcadas e todos possam participar com interesse e prazer, num primeiro momento a leitura pode ser um jogo de adivinhação.

Há 50\% de possibilidades de se acertar ou de se errar, entra-se no texto, sem saber o que existe adiante. $\mathrm{O}$ título exibe a primeira pista. A partir dele, levantam-se hipóteses, fazem-se predições. Um rápido olhar sobre o texto oferece novas pistas: é um poema, um anúncio, um conto, uma receita? Os jogadores não devem temer o erro. Caso as primeiras hipóteses não estejam corretas, ele pode e deve refazê-las, voltar atrás. No jogo da leitura, o erro é aceito, previsto, pois ele possibilita o caminhar.

\section{O LEITOR JOGADOR}

Ao levantar as primeiras hipóteses sobre o texto, o conhecimento prévio do leitorjogador ativa-se, colocando em jogo um leque de conhecimentos: lingüístico, textual, do mundo, juntamente com sua capacidade cognitiva. Ainda que em níveis mínimos e bastante heterogêneos, todos os jogadores, mesmo os iniciantes, possuem saberes referentes aos diversos domínios do conhecimento. Conhecem e praticam a língua materna, estão familiarizados com textos escritos, têm acesso a múltiplas informações transmitidas pelos diversos meios de comunicação.

O sucesso dos jogadores depende, também, em grande parte, do conhecimento dos objetivos propostos para o jogo em pauta. É a partir deles que os leitores determinam as 
etapas a serem seguidas: ir até o fim do texto, procurando a compreensão geral e global; ou parar em pontos fixados, buscando respostas parciais. Sem objetivos claros e definidos, os caminhos tornam-se longos e tortuosos.

Em um jogo de interação contínua, o leitor parte do signo, do texto, ativando seu conhecimento lingüístico e textual, para o sentido - direção semasiológica; ou, então, em ordem inversa, parte da noção, do conceito, do sentido para o texto - direção onomaseológica. Nesse movimento ascendente e descendente, do signo para a noção, da noção para o signo, nas idas e voltas, o leitor vai construindo o sentido do texto.

No jogo da leitura, informações são antecipadas e inferidas, lacunas preenchidas, sentidos construídos. As entradas para o texto são várias: o título, a natureza do texto, o conhecimento de mundo, saberes situacionais e referenciais, habilidades cognitivas. Todos esses domínios organizam-se segundo regras que são desveladas no decorrer do jogo. Regras distintas, próprias de cada domínio, mas que se relacionam, se entrelaçam, sem valor hierárquico, permitindo ao leitor escolher qual o sentido mais adequado ao texto.

Semelhante a um quebra-cabeças, as peças vão sendo encaixadas, trocadas, retiradas. A mudança de uma peça pode alterar o sentido global. Na construção e reconstrução, nas idas e vindas, na interação com jogadores mais ou menos experientes, o sentido textual se constitui.

O jogador mais experiente é o que joga há mais tempo e conhece um número maior de regras e de jogos. Na sala de aula, esse papel, certamente, cabe ao professor, que deve ter como principal objetivo fazer com que todos os jogadores, alunos-leitores, conheçam as regras do jogo, os diversos níveis e sejam capazes de jogar sem seu auxílio. Ser o jogador mais experinte significa conhecer as regras, mas não o resultado final; indi- car caminhos, propor jogadas, mas não determinar a melhor jogada; ensinar como reconhecer pistas lingüísticas e não-lingüísticas presentes no texto, mas não jogar sozinho. Jogador mais experiente, o professor sabe que se aprende sempre com outros jogadores, que trocas devem ser estimuladas e encorajadas.

Consciente de que o objetivo final é a autonomia do aluno, o professor trabalha, simultaneamente, três dimensões fundamentais que devem permear o processo de leitura: as dimensões afetiva, cognitiva e pragmática ${ }^{8}$.

A dimensão afetiva proporciona ao aluno uma sensação de prazer, de bem-estar, de fruição, de sentir-se à vontade, em segurança na sala de aula, desenvolvendo a confiança em si, em sua capacidade de realização.

A segunda dimensão, cognitiva, possibilita a manifestação do saber apreendido tornando $o$ aluno consciente das regras presentes no ato de ler, sendo capaz, de certo modo, de "teorizar" a respeito da leitura realizada.

Por último, a dimensão pragmática demonstra não só o conhecimento do objeto de estudo, mas também a capacidade de realização, em situações práticas. $\mathrm{O}$ aluno é capaz de movimentar-se com segurança no mundo da escrita.

O jogador domina o jogo, cria outros jogos, desafiando jogadores mais experientes.

Tendo como objetivo a emancipação do aluno em uma sociedade letrada, cujas relações profissionais, políticas, econômicas, sociais e de poder são regidas pela escrita, a escola desempenhará com mais eficiência sua função, considerando a leitura como um jogo que atende a necessidades básicas do homem, em sua busca de equilíbrio psíquico e participação social.

"O homem brinca unicamente quando é homem no sentido pleno da palavra, e é plenamente homem unicamente quando brinca." (Schiller) 